\title{
Epigenetic silencing of microRNA-199b-5p is associated with acquired chemoresistance via activation of JAG1-Notch1 signaling in ovarian cancer
}

\author{
Michelle X. Liu ${ }^{1}$, Michelle KY. Siu ${ }^{1}$, Stephanie S. Liu ${ }^{1}$, Judy WP. Yam², Hextan YS. \\ Ngan $^{1}$, David W. Chan ${ }^{1}$ \\ ${ }^{1}$ Department of Obstetrics and Gynaecology, LKS Faculty of Medicine, The University of Hong Kong, Hong Kong SAR, \\ P.R.China \\ 2 Department of Pathology, LKS Faculty of Medicine, The University of Hong Kong, Hong Kong SAR, P.R.China \\ Correspondence to: Hextan YS Ngan, email: hysngan@hku.hk \\ David W Chan, email: dwchan@hku.hk
}

Keywords: MiR-199b-5p, JAG1-Notch1, acquired chemoresistance, epithelial ovarian cancer

Received: October 1, $2013 \quad$ Accepted: December 3, $2013 \quad$ Published: December 4, 2013

This is an open-access article distributed under the terms of the Creative Commons Attribution License, which permits unrestricted use, distribution, and reproduction in any medium, provided the original author and source are credited.

\section{ABSTRACT:}

Epithelial ovarian cancer is a highly lethal and aggressive gynecological malignancy. The high mortality rate is due in part to the fact that many advanced cancer patients become refractory to current chemotherapeutic agents, leading to tumor recurrence and death. However, the underlying mechanisms leading to chemoresistance remain obscure. Here, we report that the loss of miR-199b-5p due to progressive epigenetic silencing leads to the activation of the JAG1-mediated Notch1 signaling cascade, thereby leading to the development of acquired chemoresistance in ovarian cancer. Using miRCURY LNA ${ }^{\mathrm{TM}}$ microRNA array and Q-PCR analyses of two pairs of cisplatin-sensitive and -resistant ovarian cancer cell lines, we identified miR-199b-5p as significantly down-regulated in cisplatin-resistant ovarian cancer cells and confirmed that miR-199b-5p is clinically associated with advanced and poor survival ovarian cancers. Interestingly, the loss of miR-199b-5p could be restored by 5-Aza-dC-mediated demethylation, and methylated specific PCR (MS-PCR), bisulfitesequencing and pyrosequencing revealed that the promoter region of $\mathrm{miR}-199 \mathrm{~b}-5 \mathrm{p}$ was hypermethylated. Computational and mechanistic analyses identified JAG1 as a primary target of miR-199b-5p. Notably, the reduced expression of miR-199b-5p was found to be inversely correlated with the increased expression of JAG1 using an ovarian cancer tissue array. Enforced expression of miR-199b-5p sensitized ovarian cancer cells to cisplatin-induced cytotoxicity both in vitro and in vivo. Conversely, reexpression of miR-199b-5p and siRNA-mediated JAG1 knockdown or treatment with Notch specific inhibitor Y-secretase (GSI) attenuated JAG1-Notch1 signaling activity, thereby enhancing cisplatin-mediated cell cytotoxicity. Taken together, our study suggests that the epigenetic silencing of miR-199b-5p during tumor progression is significantly associated with acquired chemoresistance in ovarian cancer through the activation of JAG1-Notch1 signaling.

\section{INTRODUCTION:}

Epithelial ovarian cancer is one of the most lethal malignancies in females worldwide. The high mortality rate of this disease is due to its poor prognosis and the fact that the majority of patients are diagnosed at advanced stages. Therefore, chemotherapy combined with surgical cytoreduction is the standard initial management for ovarian cancer patients at advanced stages [1,2]. Platinum-based chemotherapy is the standard first-line regimen for advanced ovarian cancer [3, 4]. The clinical response rate is initially high, but the subsequent relapse 
and repetitive challenges of chemotherapeutic agents leads to the development of acquired chemoresistance [5]. Such acquired chemoresistance is the major obstacle to the clinical management of ovarian cancer $[6,7]$. However, the molecular mechanisms underlying acquired chemoresistance remain largely unknown, underlying the urgent need to identify the associated molecular mechanisms to explore alternative therapeutic strategies.

Acquired chemoresistance, also called as extrinsic chemoresistance, develops secondary to genetic and epigenetic alterations in cell proliferation, apoptosis, DNA repair, etc., after the administration of repetitive cycles of chemotherapy $[5,8,9]$. Genetic changes refer to the changes in the DNA sequence, including mutation, deletion, amplification, and translocation, whereas epigenetic alterations include DNA methylation, histone modifications and microRNA (miRNA) regulation. Emerging evidence suggests the importance of miRNAs in developing acquired chemoresistance in various human cancers [10-12]. The dysregulation of miRNAs alters a network of functional targets and signaling pathways, resulting in acquired chemoresistance in human cancers $[10,11]$. For examples, up-regulation of miR-21 causes acquired trastuzumab resistance by repressing PTEN expression during long-term exposure to trastuzumab antibody in breast cancer [13], and the repetitive application of cisplatin (CDDP) to non-small cell lung cancer (NSCLC) A549 cells induces an increase in miR630, which enhances cytoprotection against CDDP and carboplatin by inhibiting the p53 signaling pathway [14]. This evidence prompted us to hypothesize that some miRNAs may be involved in developing acquired chemoresistance during ovarian cancer progression.

In this study, we used the miRCURY LNA ${ }^{\mathrm{TM}}$ microRNA Array followed by a series of in vitro and in vivo functional and biochemical analyses to identify miR$199 b-5 p$ as being associated with cisplatin resistance in ovarian cancer cells. Importantly, our finding provides a novel molecular mechanism of epigeneticmediated acquired chemoresistance in ovarian cancer by which miR-199b-5p is frequently silenced by DNA hypermethylation, thereby leading to the activation of JAG1-Notch1 signaling in ovarian cancer progression and acquired chemoresistance.

\section{RESULTS:}

\section{Identification of miR199b-5p as a putative miRNA candidate involved in the chemoresistance of ovarian cancer}

To investigate the dysregulated miRNAs in ovarian cancer with acquired chemoresistance, microRNA profiling was performed using the miRCURY LNA ${ }^{\mathrm{TM}}$
miRNA array on two pairs of ovarian cancer cell lines (cisplatin-sensitive: A2780s and OV2008 vs. cisplatinresistant: A2780cp and $\mathrm{C} 13^{*}$ ) [15]. Our results revealed that there were 35 upregulated miRNAs ( $>2$-fold) and 45 downregulated miRNAs $(<0.5$-fold) with statistical significance (data not shown). Among these dysregulated miRNAs, 21 upregulated miRNAs and 10 downregulated miRNAs were commonly found in both pairs of cell lines (Supplementary Fig. S1). In this study, the downregulated miRNAs in chemoresistant ovarian cancer cells were studied. Of 10 downregulated miRNAs, 5 miRNAs (miR-10b, miR-99a, miR-193a-3p, miR-199b-5p and miR-675) were selected for verification of the response to cisplatin-induced cell cytotoxicity via transient transfection of their pre-miRNA-expressing plasmids. Among these 5 candidates, XTT cell proliferation assay demonstrated that miR-199b-5p exhibited a remarkable

A

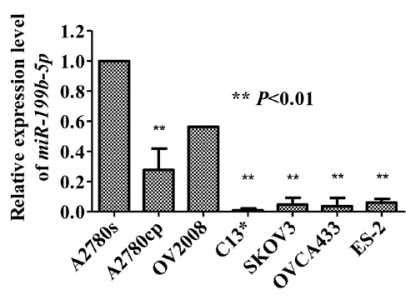

B
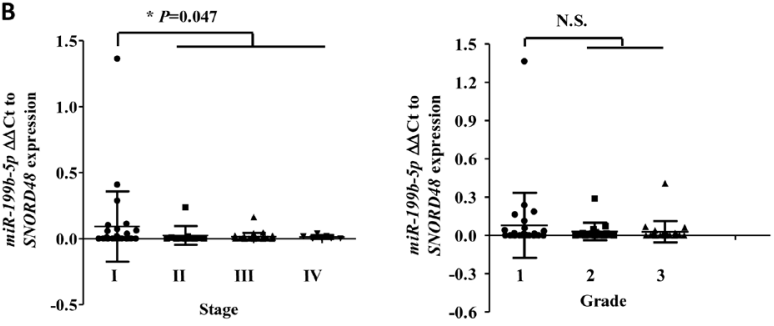

C

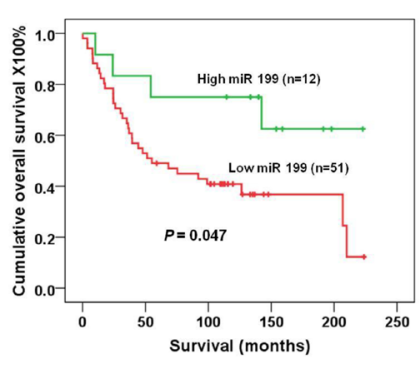

Fig 1: Loss of miR199b-5p is involved in acquired chemoresistance and advanced-stage ovarian cancer. (A) miR-199b-5p expression was measured by quantitative RTPCR in a panel of ovarian cancer cell lines: A2780s, A2780cp, OV2008, C13*, SKOV3, OVCA429, OVCA433, and ES-2. The results are reported as the mean \pm SD of three independent experiments performed in triplicate, ${ }^{* *} \mathrm{P}<0.01$. (B) Comparison of miR-199b-5p expression in early-stage (Stage I, N=28) vs. advanced-stage (Stage II, III and IV, N =51) ovarian cancer $(\mathrm{P}=0.047)$ and in low-grade vs. high-grade disease as determined by Q-PCR. (C) Comparison of the survival curve of ovarian cancer patients with high $(n=12)$ and low levels $(n=51)$ of miR$199 \mathrm{~b}-5 \mathrm{p}$. The relative expression level of miR-199b-5p (0.024) was used as a cutoff point. $* \mathrm{P}=0.047$ 
increase in the cisplatin-mediated cell cytotoxicity of A2780cp and C13* cells (data not shown). As miR$199 b-5 p$ could sensitize ovarian cancer cells to cisplatininduced cytotoxicity, we hypothesized that the loss of the miR-199b-5p is involved in chemoresistance of ovarian cancer. To validate this hypothesis, Q-PCR was performed to evaluate the expression of miR-199b-5p. We confirmed that miR-199b-5p was downregulated in chemoresistant ovarian cancer cells A2780cp and C13* compared with their chemosensitive counterparts A2780s and OV2008 (Fig. 1A). In addition to these cell lines, the expression of miR-199b-5p was also reduced in other chemoresistant ovarian cancer cell lines: SKOV3, OVCA433 and ES-2 [16-18] (Fig. 1A). We observed a trend of progressively diminishing miR-199b-5p expression (measured as $2-\Delta \mathrm{Ct}$ ) from early to advanced stages and from low to high grade ovarian cancer (Fig. 1B). Importantly, the downregulated miR-199b-5p was significantly correlated with poor survival rate $(\mathrm{P}=0.047)$ (Fig. 1C). These results indicate that the expression of miR-199b-5p is gradually silenced in ovarian cancer progression and that downregulated miR$199 b-5 p$ is significantly associated with chemoresistance and poor survival of ovarian cancer patients.

\section{Loss of miR-199b-5p is attributed to promoter hypermethylation in ovarian cancer}

Recent evidence suggests that DNA methylation typically silences expression of miRNAs in cancer progression $[19,20]$. To investigate whether the downregulation of miR-199b-5p was attributed to
A

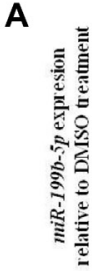

C

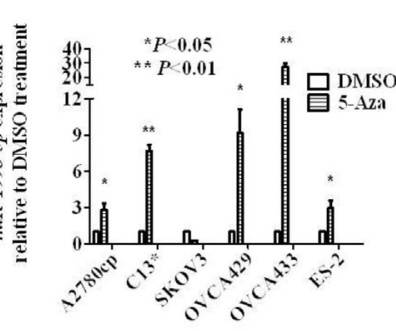

$\underline{\mathrm{A2780}} \underline{\mathrm{A2780} \mathrm{cP} \triangle \mathrm{C} 13 * 0 \mathrm{OVCA} 43 \mathrm{SKOV} 3}$

B

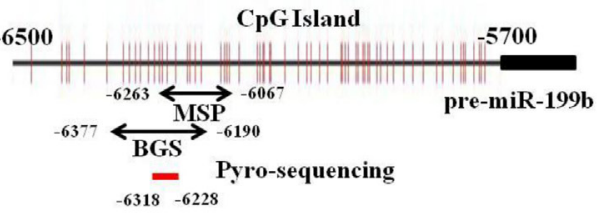

D

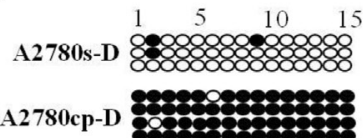

A2780cp-Aza

E

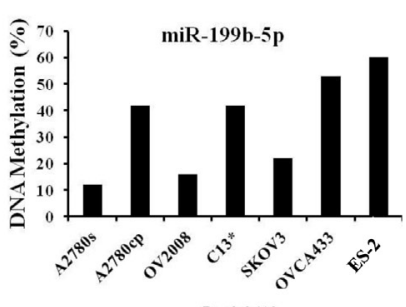

$\mathbf{F}$
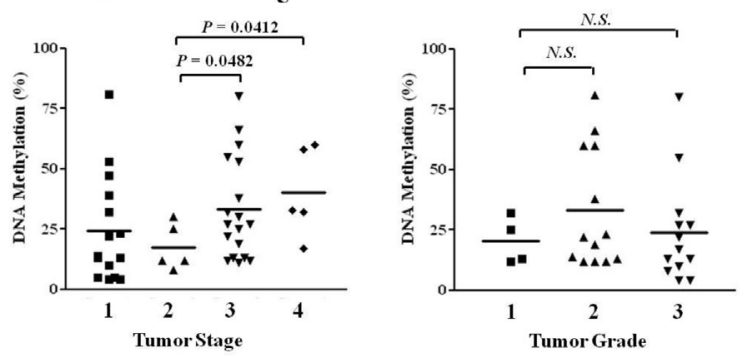

Fig 2: Hypermethylation silences miR-199b-5p expression in ovarian cancer. (A) The expression of miR-199b-5p could be restored in cisplatin-resistant ovarian cell lines upon 5-Aza-dC mediated demethylation treatment $(* \mathrm{P}<0.05$, $* * \mathrm{P}<0.01)$. (B) Schematic illustration of $\mathrm{CpG}$ islands in the promoter region of miR-199b-5p. Vertical lines indicate CpG sites. The arrows indicate the MS-PCR, BGS and pyrosequencing (-6318 to -6228) regions. (C) Promoter methylation status of miR-199b-5p was evaluated by MS-PCR in ovarian cancer cells upon treatment of 5-Aza-dC-mediated demethylation. (D) BGS evaluation of the promoter methylation status of miR-199b$5 \mathrm{p}$ in ovarian cancer cells A2780s, A2780cp and SKOV3 with/without 5-Aza-dC mediated demethylation. Each row of circles indicates a single clone. Each circle indicates a $\mathrm{CpG}$ site. Filled, methylated $\mathrm{CpG}$ site. Unfilled, unmethylated CpG site. (E) Pyrosequencing analysis revealed that methylation density of ovarian cancer cell lines. (F) Pyrosequencing results of ovarian cancer samples indicated that there was a progressive increase in the methylation status with tumor stage (stage 3 vs. stage $2, \mathrm{P}=0.0482$; stage 4 vs. stage 2 , $\mathrm{P}=0.0412$ ), whereas there was no significance relationship between the methylation status and tumor grade. Each dot represents the methylation percentage of each clinical sample. 
promoter hypermethylation in ovarian cancer, 6 ovarian cancer cell lines were treated with the DNA demethylation reagent 5-Aza-2'-deoxycitidine (5-Aza-dc). Q-PCR analysis demonstrated that the expression of miR-199b$5 p$ was significantly restored in 5 out of 6 ovarian cancer cell lines after 5-Aza-dc mediated demethylation (Fig. 2A). Further analysis of the methylation status of the promoter region of miR-199b-5p was performed by bisulfite genomic sequencing (BGS) and methylationspecific PCR (MS-PCR). A CpG island located -6,500 to $-5,000$ bp upstream of pre-miR-199b was identified (Fig. 2B). MS-PCR and BGS were employed to evaluate the DNA methylation status within the $\mathrm{CpG}$ islands of the promoter region of miR-199b-5p in ovarian cancer cell lines. The MS-PCR results revealed that an increase in DNA methylation was frequently observed in the promoter region of miR-199b-5p in chemoresistant ovarian cancer cell lines (A2780cp, C13* and OVCA433), whereas increased DNA methylation status could be reversed with 5-Aza-dc treatment (Fig. 2C). In contrast, less DNA methylation was observed in chemosensitive A2780s cells and in SKOV3 cells in which the expression of miR$199 \mathrm{~b}-5 \mathrm{p}$ could not be restored by 5 -Aza-dc demethylating activity (Fig. 2C). The DNA methylation status of the miR-199b-5p promoter was further validated by BGS and pyrosequencing analyses, and the results were consistent with the above findings (Figs. 2D and 2E). In clinical samples, pyrosequencing analysis also revealed that DNA methylation was gradually increased in parallel with the tumor stage (Stage 2 vs. Stage 3, $\mathrm{P}=0.0482$; Stage 2 vs. Stage $4, \mathrm{P}=0.0412$ ) (Fig. $2 \mathrm{~F}$ ). However, due to the small patient cohort, a significant correlation between DNA methylation and tumor grade could not be found (Fig. 2F). Collectively, these data suggest that the downregulation of miR-199b-5p is attributed to increased DNA methylation during repetitive chemotherapeutic challenges and ovarian cancer progression.

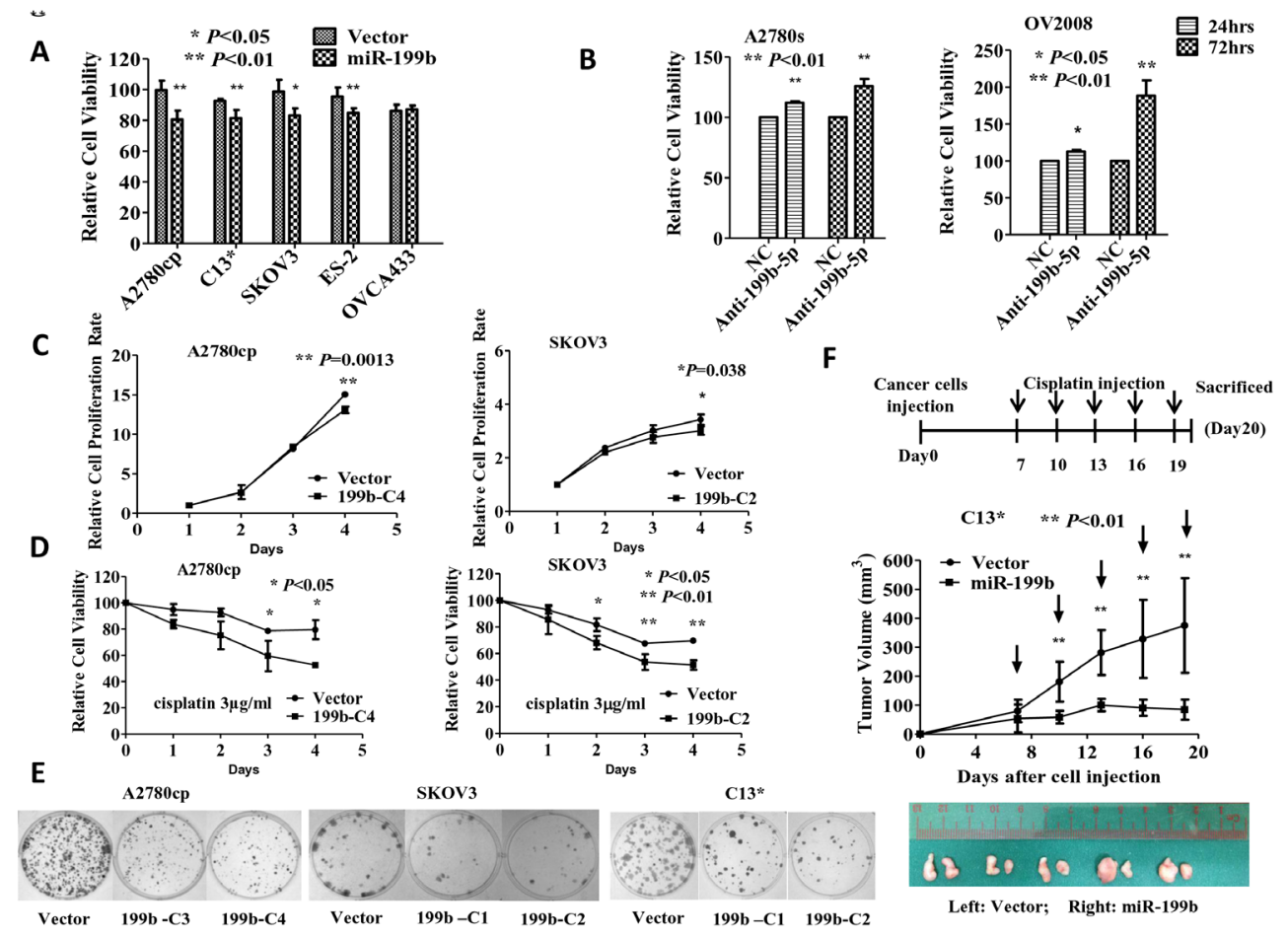

Fig 3: MiR-199b-5p sensitizes chemoresistant ovarian cancer cells to cisplatin-induced cytotoxicity in vitro and in vivo. (A) XTT cell proliferation assay revealed that ectopic expression of miR-199b-5p significantly reduce cell viability from $95-99 \%$ to $80-85 \%$ in A2780cp, C13*, SKOV3 and ES-2 cells upon cisplatin treatment ( $3 \mu \mathrm{g} / \mathrm{ml}, 24$ hours). (B) XTT cell proliferation assay revealed that depletion of miR-199b-5p increased cell viability from $11 \%$ to $25 \%$ in A2780s cells and $12 \%$ to $88 \%$ in OV2008 upon cisplatin treatment $(1 \mu \mathrm{g} / \mathrm{ml})$ at $24 \mathrm{~h}$ and $72 \mathrm{~h}$ compared with the negative control. (C \& D) XTT cell proliferation assay demonstrated that the stable expression of miR-199b-5p inhibited cell proliferation by $15 \%$ in A2780cp cells and 13\% in SKOV3 cells but further inhibited the cell viability $19-26 \%$ in A2780cp and $13-18 \%$ in SKOV3 upon cisplatin treatment $(3 \mu \mathrm{g} / \mathrm{ml})$. (E) The focus formation assay revealed that stable expression of miR-199b-5p caused a 40\% reduction in foci formation in C13* and SKOV3 cells and an 80\% reduction in A2780cp cells upon cisplatin treatment $(3 \mu \mathrm{g} / \mathrm{ml}, 14$ days). The results are reported as the mean $\pm \mathrm{SD}$ of three independent experiments performed in triplicate, ${ }^{*}, \mathrm{P}<0.05,{ }^{*}, \mathrm{P}<0.01$. (F) miR-199b-5p stable expression (C2) and vector control C13* cells were inoculated subcutaneously into nude mice. The mice were i.p. injected with cisplatin $(5 \mathrm{mg} / \mathrm{kg})$ every three days beginning on day 7 when the palpable tumor was formed. The tumor size was calculated and reported as the mean tumor volume $\pm \mathrm{SE}$ of each group of five mice. The miR-199b-5p stable expression transfectant $(\mathrm{C} 2)$ resulted in a significantly slower tumor growth rate compared with the vector control. Vertical arrows indicate the time of cisplatin injection. Points, mean of 5 mice. Bars, SD. N=5, ** $\mathrm{P}<0.01$. 


\section{Loss of miR199b-5p is associated with cisplatin- resistant ovarian cancer cells}

To study the functional role of miR-199b-5p in the chemoresistance of ovarian cancer, the pre-miR-199b$5 \mathrm{p}$ expression plasmid (pmR-ZsGreen1-miR-199b-5p) was transiently transfected into five chemoresistant ovarian cancer cells (A2780cp, C13*, SKOV3, ES-2 and OVCA433). Upon treatment with cisplatin $(3 \mu \mathrm{g} / \mathrm{ml})$, the XTT cell proliferation assay revealed that enforced expression of miR-199b-5p significantly reduced cell viability by $15-20 \%$ in A2780cp, C13*, SKOV3 and ES-2 cells compared with their vector controls (Fig. 3A). In contrast, depletion of miRNA-199b-5p in A2780s and OV2008 by a specific miRNA inhibitor (Ambion Product ID, AM10553) (Supplementary Fig. S2a) dramatically increased cell viability from $25 \%$ to $88 \%$ in A2780s and OV2008 cells, respectively, compared with their controls upon cisplatin treatment (Fig. 3B).

To study whether miR-199b-5p is functionally relevant in the inhibition of ovarian cancer cell growth, stable expression of miR-199b-5p in A2780cp and SKOV3 cells (Supplementary Fig. S2B) was observed suppressed cell proliferation by $15 \%$ in A2780cp and by $13 \%$ in SKOV3 cells (Fig. 3C). Furthermore, upon treatment with cisplatin, the miR-199b-5p stably expressing cells in A2780cp (C4) and SKOV3 (C2) exhibited reduced cell viability, approximately $15-20 \%$ compared with the vector controls (Fig. 3D). By focus formation assay, the miR-199b-5p stably expressing cells (A2780cp C3 and $\mathrm{C} 4, \mathrm{C} 13 * \mathrm{C} 1$ and $\mathrm{C} 2$, SKOV $3 \mathrm{C} 1$ and $\mathrm{C} 2$ ) exhibited 40$80 \%$ reduced foci formation in both number and size upon cisplatin treatment (Fig. 3E) (Supplementary Fig. S2C). These results indicate that miR-199b-5p is capable of suppressing ovarian cancer cell growth and sensitizing ovarian cancer cells to be cisplatin-induced cytotoxicity.

To confirm the role of miR-199b-5p in enhancing the sensitivity of ovarian cancer cells to cisplatin-mediated cytotoxicity in vivo, the miR-199b-5p stably expressing ovarian cancer cell $\mathrm{C} 13^{*}(\mathrm{C} 2)$ and vector control were subcutaneously (s.c.) injected into the right and left flanks of mice, respectively. The tumor-bearing mice were then treated with $5 \mathrm{mg} / \mathrm{kg}$ cisplatin every three days beginning on Day 7. On Day 19, the size of tumor from the miR199b-5p expressing cells was profoundly smaller $(\sim 70 \%)$ than the vector control (Fig. 3F). Taken together, these data suggest that the loss of miR-199b-5p is associated with increased tumor growth and the cisplatin resistance of ovarian cancer cells.

\section{JAG1 is a direct target of miR199b-5p in ovarian cancer}

To identify the potential targets regulated by miR199b-5p, bioinformatic databases such as TargetScan and miRanda were searched. Among the list of potential targets, JAG1 was identified as a target of miR-199b-5p. JAG1 contains a highly conserved miR-199b-5p binding site at nucleotides 135-141 in its 3'UTR and is a transmembrane protein acting as a key ligand of Notch receptors in ovarian cancer $[16,21]$. To further prove whether JAG1 acts as a primary target of miR-199b-5p, luciferase reporter plasmids containing the JAG1 3'UTR wild-type binding sites pmirGLO-JAG1-3'UTR-WT (ACACUGG) and the mutated binding sites pmirGLO-JAG1-3'UTRMUT (TCTCAGG) (Fig. 4A) were constructed and cotransfected with an miR-199b-5p mimic (pmR-ZsGreen1miR-199b-5p) in HEK293 cells. The result demonstrated that co-transfection of pmirGLO-JAG1-3'UTR-WT and pmR-ZsGreen1-miR-199b-5p could reduce luciferase activity by $38 \%$ compared with the vector control. In contrast, co-transfection of pmirGLO-JAG1-3'UTR-MUT and pmR-ZsGreen 1-miR-199b-5p exhibited no difference in luciferase activity compared with the vector control (Fig. 4B). Moreover, western blot analysis revealed that the expression of JAG1 was upregulated and was inversely associated with the decreased expression level of miR199b-5p in ovarian cancer cell lines such as C13*, SKOV3 and ES-2 (Fig. 4C). Enforced expression of miR-199b-5p significantly and dose dependently reduced the expression of JAG1 in HEK293 cells as well as in two chemoresistant ovarian cancer cell lines, C13* and SKOV3 (Fig. 4D). Intriguingly, the enforced expression of miR-199b-5p profoundly reduced HES1 luciferase reporter activity in SKOV3 cells by $35 \%$ (Fig. 4E), indicating the JAG1Notch1 signaling cascade could be suppressed by miR$199 b-5 p$ in ovarian cancer cells. These findings suggest that JAG1 is a direct target of miR-199b-5p and that reduced miR-199b-5p and increased JAG1 are involved in ovarian cancer chemoresistance.

To verify whether the upregulation of JAG1 was attributed to the loss of miR-199b-5p in ovarian cancer, both in situ hybridization (ISH) and immunohistochemistry (IHC) were performed to examine the expression level of miR-199b-5p and JAG1, respectively, on a commercial human ovarian cancer tissue array (OVC1021, Pantonmics). The results revealed that low expression of miR-199b-5p ( $\leq 2$-fold) was significantly correlated with high expression of JAG1 ( $>5$-fold) (Fig. $4 \mathrm{~F}, \mathrm{~N}=97, \mathrm{P}=0.013)$. Intriguingly, clinicopathological analysis revealed that both low expression of miR-199b$5 p$ ( $\leq 2$-fold) and high expression of JAG1 ( $>5$-fold) were significantly correlated with high-grade tumors $(\mathrm{p}=0.014$ for miR-199b-5p and $\mathrm{P}<0.001$ for JAG1) (Table 1). These results further indicate that the downregulation of miR$199 \mathrm{~b}-5 \mathrm{p}$ contributes to the upregulation of JAG1 and is involved in aggressive ovarian cancer, such as high-grade tumors. 


\section{JAG1 is required for ovarian cancer cell growth and cisplatin-induced cytotoxicity}

Aberrant upregulation of JAG1 has been reported to be associated with human cancer development and progression [16, 22, 23]. To study the function of JAG1 in ovarian cancer oncogenesis and chemoresistance, we evaluated the expression of JAG1 on a panel of ovarian cancer cell lines. Western blot analysis demonstrated that JAG1 was upregulated in most ovarian cancer cell lines (Fig. 4C). Intriguingly, higher JAG1 expression was exclusively observed in cisplatin-resistant ovarian cancer cell lines (C13*, SKOV3 and A2780cp) compared with their corresponding cisplatin-sensitive cell lines (OV2008 and A2780s) (Fig. 4C). A long exposure time in western blotting revealed that A2780cp cells exhibited a higher expression level of JAG1 than did A2780s (Supplementary

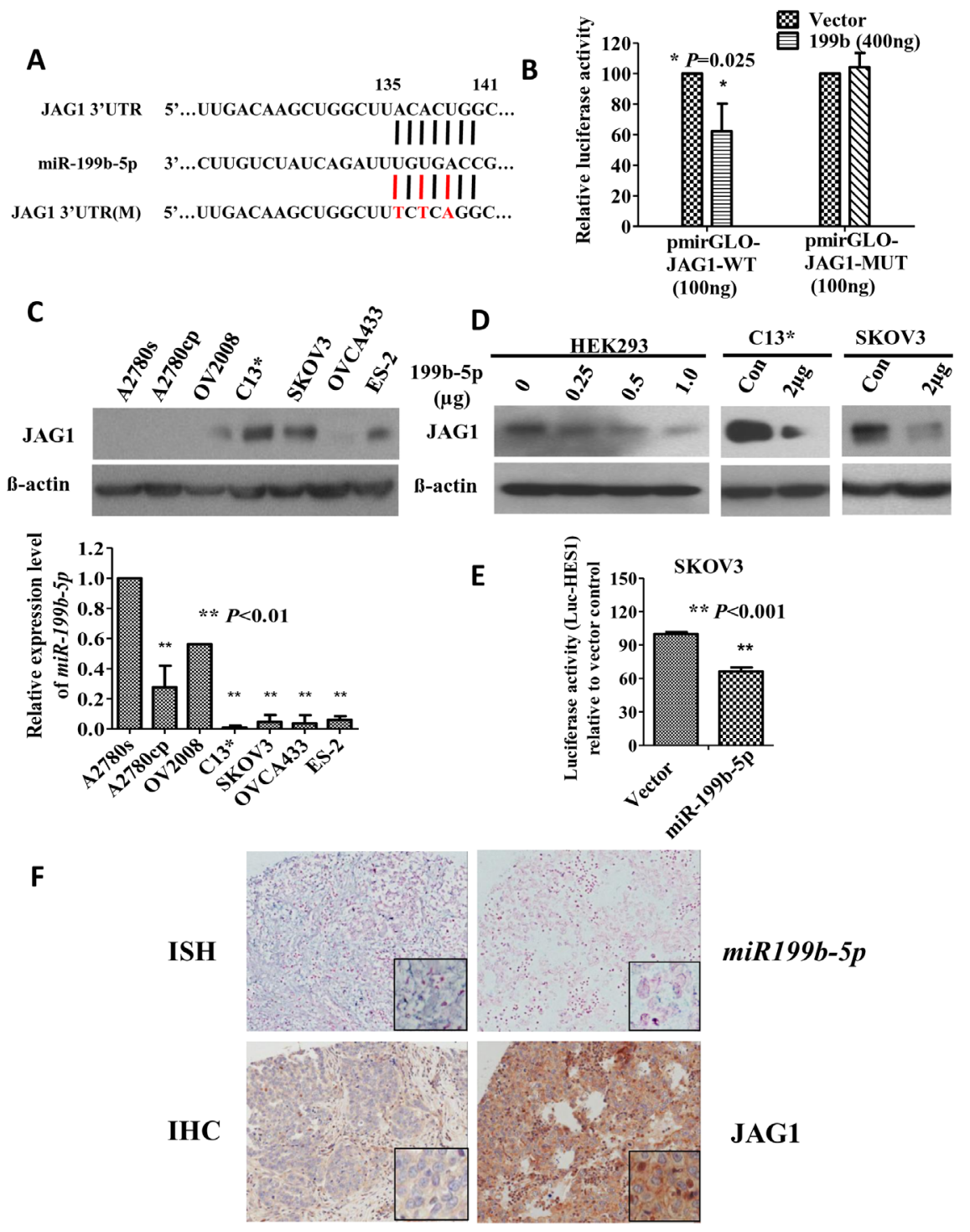

Fig 4: JAG1 is a direct target of mir199b-5p and a key factor mediating Notch1 signaling activity in chemoresistant ovarian cancer. (A) A schematic diagram indicating the wild-type and mutated type binding sites of miR-199b-5p in the JAG1 3'UTR. (B) The luciferase reporter assay demonstrated that co-transfection of the JAG1 3'UTR wild-type pmir-GLO-JAG1-WT but not the mutated pmirGLO-JAG1-MUT plasmids (100 ng) with pmR-ZsGreen1-miR-199b-5p (400 ng) resulted in a 38\% reduction in the luciferase activity compared with the vector control. *, $\mathrm{P}=0.025$. (C) Both western blot and Q-PCR results indicated a reciprocal expression pattern of JAG1 and miR-199b-5p in a panel of ovarian cancer cell lines. (D) Transient transfection of pmR-ZsGreen 1-miR-199b-5p reduced the expression of JAG1 in HEK293 cells in a dose-dependent manner and in chemoresistant C13* and SKOV3 cells. (E) Co-transfection of miR-199b-5p reduced HES1 luciferase activity by 35\% compared with the vector control in SKOV3, expressing a relatively higher level of JAG1. (F) Representative pictures showing an inverse relationship between the expression levels of miR-199b-5p and JAG1 examined by ISH and $\mathrm{IHC}$ analyses in a commercial ovarian cancer tissue array (OVC1021, N=97, $\mathrm{P}=0.013)$. Two-fold and 5-fold changes in expression were used as cutoff level for miR-199b-5p and JAG1, respectively, in the statistical analysis. 
Table 1: Clinicopathological correlation of the expression of JAG1 in an ovarian cancer tissue array (OVC1021)

\begin{tabular}{|l|l|l|l|l|}
\hline \multirow{2}{*}{ Parameters } & \multirow{2}{*}{$(=97)$} & \multicolumn{4}{|l|}{ JAG1 expression } \\
\cline { 3 - 6 } & & $\leq 5$-fold & $>5$-fold & p-value \\
\hline Grade & \multicolumn{5}{|l|}{} \\
\hline Low (1+2) & 50 & $23(46 \%)$ & $27(54 \%)$ & \\
\hline High (3) & 46 & $4(9 \%)$ & $42(91 \%)$ & $<0.001^{*}$ \\
\hline Stage \\
\hline Early (1+2) & 73 & $18(25 \%)$ & $55(75 \%)$ & \\
\hline Late (3) & 24 & $10(42 \%)$ & $14(58 \%)$ & 0.126 \\
\hline Metastasis & 24 & $11(46 \%)$ & $13(54 \%)$ & \\
\hline Yes & 73 & $17(23 \%)$ & $56(77 \%)$ & $0.042 *$ \\
\hline No &
\end{tabular}

Fig. S3A). Importantly, the higher expression of JAG1 in A2780cp was accompanied by higher levels of Notch1, suggesting that Notch1 signaling activity was higher in A2780cp (Supplementary Fig. S3B). To examine the effect of JAG1 on cisplatin-resistance, one of the cisplatin-sensitive ovarian cancer cell lines, A2780s, was transiently transfected with JAG1 at variable doses $(0.5$, 1.0, and $2.0 \mu \mathrm{g}$ ) (Fig. 5A). An XTT cell proliferation assay revealed that enforced expression of JAG1 could significantly increase the cell proliferation rate by $29 \%$ and enhance the cell viability by $40 \%$ upon treatment with cisplatin compared with the vector control (Fig. 5B). Conversely, two chemoresistant cell lines, $\mathrm{C} 13^{*}$ and SKOV3, expressing a relatively higher level of JAG1 were selected for siRNA-mediated knockdown. An XTT cell proliferation assay indicated that the cell viability was remarkably reduced by $15-20 \%$ in $\mathrm{C} 13^{*}$ cells and by 10 $15 \%$ in SKOV3 cells upon cisplatin treatment compared with their scrambled controls (Fig. 5C). These data suggest that JAG1 could enhance the cell proliferation and cell viability of ovarian cancer cells to cisplatin-induced cell cytotoxicity.

\section{JAG1 enhances the chemoresistance of ovarian cancer cells by activating Notch1 signaling activity}

JAG1 acts as a key ligand of the Notch1 receptor in cancer development [22, 24, 25]. More importantly, Notch1 signaling has been shown to be involved in chemoresistance in numerous human cancers [26-

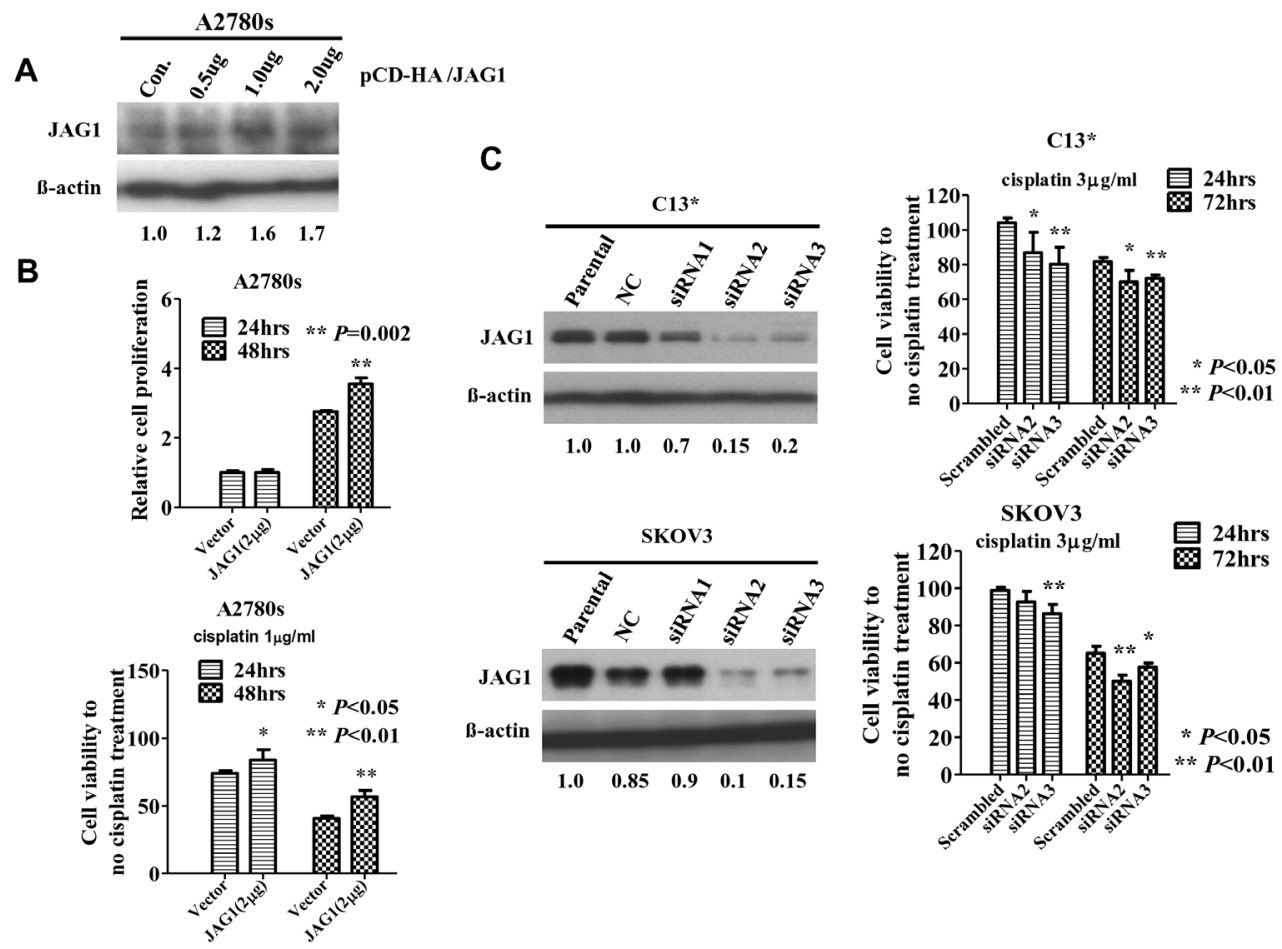

Fig 5: JAG1 enhances ovarian cancer cell growth and cisplatin-resistance. (A) Western blot analysis demonstrating the transient transfection of JAG1 (pCD-HA/JAG1) in A2780s cells. (B) XTT cell proliferation assay demonstrated that enforced expression of JAG1 increased the cell proliferation rate by $29 \%$ and increased cell viability by up to $40 \%$ in A2780s cells upon cisplatin treatment ( $1 \mu \mathrm{g} /$ $\mathrm{ml}$ ). (C) Western blot analysis revealed that two out of three siRNAs (siRNA2 and siRNA3) remarkably reduced JAG1 expression by 80$85 \%$ in $\mathrm{C} 13 *$ and $70-75 \%$ in SKOV3 cells compared with scrambled controls (NC) (left panel). XTT cell proliferation assay demonstrated that depletion of JAG1 by siRNA reduced cell viability by $15-20 \%$ in C13* cells and $10-15 \%$ in SKOV3 cells upon cisplatin treatment (3 $\mu \mathrm{g} / \mathrm{ml}$ ) (right panel). The results are expressed as the mean $\pm \mathrm{SD}$ of three independent experiments performed in triplicate. ${ }^{*}, \mathrm{P}<0.05, * *$, $\mathrm{P}<0.01$. 
28]. Hence, we speculated that JAG1-mediated Notch1 signaling activity is involved in ovarian cancer oncogenesis and chemoresistance. To this end, a luciferase reporter assay for the JAG1 expression plasmid (pCD-HA/ JAG1) and the HES1 luciferase reporter plasmid (pHES1luc) [29] was performed in OV2008 cells. HES1 is a well- known downstream target of the Notch1 receptor, and the activation of HES1 represents the activity of Notch1 signaling [30]. The luciferase reporter assay revealed that transient transfection of JAG1 $(1 \mu \mathrm{g})$ increased HES1 luciferase activity by $30 \%$ in OV2008 cells, suggesting that JAG1 is capable of activating Notch1 signaling
A

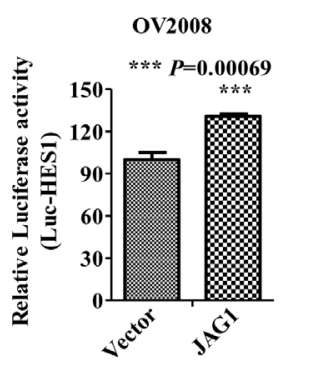

C
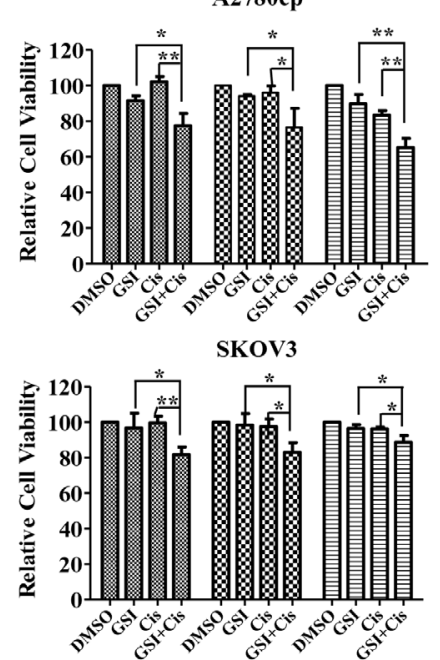

D
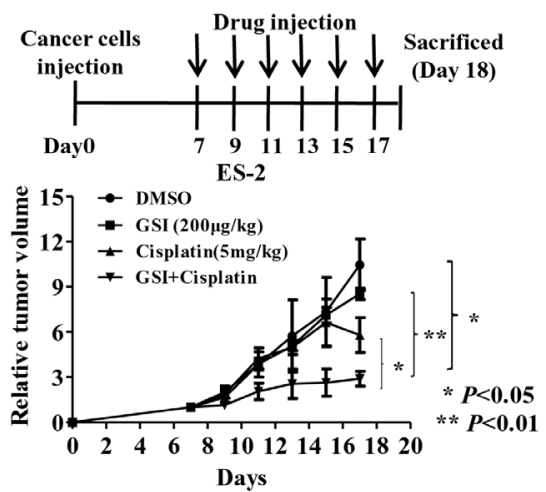

B

Notch1

B-actin
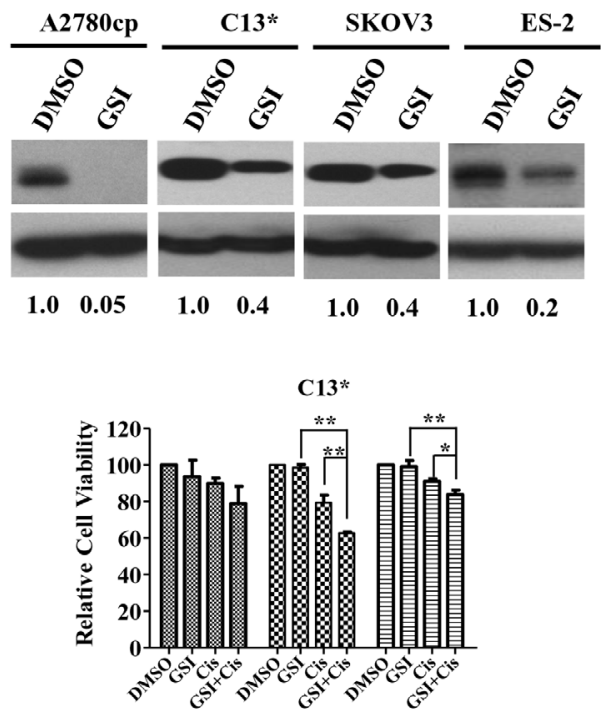

ES-2
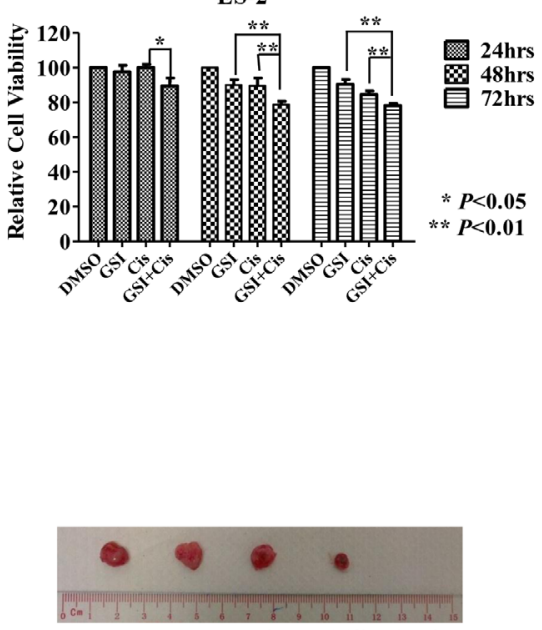

DMSO GSI Cisplatin GSI + Cisplatin

Fig 6: JAG1 enhances the chemoresistance of ovarian cancer cells by activating Notch1 signaling activity. (A) HES1 luciferase reporter assay demonstrated that JAG1 was able to increase HES1 luciferase activity by $30 \%$ compared with the vector control in OV2008. (B) Western blot analysis revealed that GSI inhibited the expression of the Notch1 active domain by $60-95 \%$ in A2780cp, C13*, SKOV3 and ES-2 cells. (C) XTT cell proliferation assay demonstrated that GSI or cisplatin reduced cell viability by $5-10 \%$ in A2780cp, C13*, SKOV3 and ES-2 cells after 24 to 72 hrs. Co-treatment with GSI and cisplatin dramatically reduced cell viability by $17-38 \%$ in the above cell lines after $24 \mathrm{hrs}$ to $72 \mathrm{hrs}$ when compared with the DMSO control. Dose of DMSO, $10 \mu \mathrm{M}$; GSI, $10 \mu \mathrm{M}$; cisplatin, $3 \mu \mathrm{g} / \mathrm{ml}$; GSI, $10 \mu \mathrm{M},+$ cisplatin, $3 \mu \mathrm{g} / \mathrm{ml}$. The results are reported as the mean $\pm \mathrm{SD}$ of three independent experiments performed in triplicate. ${ }^{*}, \mathrm{P}<0.05$, **, $\mathrm{P}<0.01$. (D) Blocking Notch1 signaling by GSI enhances cisplatin-mediated cell cytotoxicity in a tumor xenograft mouse model. ES-2 cells were injected subcutaneously into nude mice. The tumor-bearing nude mice were separated into 4 test groups on day 7 and were i.p. injected with DMSO, GSI $(200 \mathrm{ng} / \mathrm{kg})$, cisplatin $(5 \mathrm{mg} / \mathrm{kg}$ ) or a combination of GSI and cisplatin every two days. The tumor size was monitored and calculated as the mean tumor volume $\pm \mathrm{SE}$ of each group. The group receiving both GSI and cisplatin exhibited the slowest tumor growth rate. The representative picture shows the tumor size of each group. Vertical arrows indicate the time of drug injection. Points show the mean of 3 mice of each group. Bars, $\mathrm{SD}$. $\mathrm{N}=3,{ }^{*} \mathrm{P}<0.05 ; * * \mathrm{P}<0.01$. 
Table 2: Clinicopathological correlation of the expression of miR199b-5p in an ovarian cancer

tissue array (OVC1021)

\begin{tabular}{|c|c|c|c|c|}
\hline \multirow{2}{*}{ Parameters } & \multirow{2}{*}{$\mathrm{n}(=97)$} & \multicolumn{3}{|c|}{ miR199b-5p expression } \\
\hline & & $\leq 2$-fold & $>2$-fold & p-value \\
\hline \multicolumn{5}{|l|}{ Grade } \\
\hline Low $(1+2)$ & 50 & $18(36 \%)$ & $32(64 \%)$ & \\
\hline High (3) & 46 & $29(63 \%)$ & $17(37 \%)$ & $0.014 *$ \\
\hline \multicolumn{5}{|l|}{ Stage } \\
\hline Early $(1+2)$ & 73 & $38(52 \%)$ & $35(48 \%)$ & \\
\hline Late (3) & 24 & $10(42 \%)$ & $14(58 \%)$ & 0.482 \\
\hline \multicolumn{5}{|l|}{ Metastasis } \\
\hline Yes & 24 & $10(42 \%)$ & $14(58 \%)$ & \\
\hline No & 73 & $38(52 \%)$ & $35(48 \%)$ & 0.482 \\
\hline \multicolumn{5}{|l|}{ JAG1 } \\
\hline$<5$ folds & 28 & $8(29 \%)$ & $20(71 \%)$ & \\
\hline$>5$ folds & 69 & $40(58 \%)$ & $29(42 \%)$ & $0.013^{*}$ \\
\hline
\end{tabular}

activity (Fig. 6A).

To further investigate the functional role of Notch1 signaling in the chemoresistance of ovarian cancer, a $\gamma$-secretase inhibitor (GSI XXI, compound E, $10 \mu \mathrm{M}$ ) was used to inhibit Notch1 activity in the chemoresistant ovarian cancer cells A2780cp, C13*, SKOV3 and ES-2 (Fig. 6B). Upon treatment with either GSI or cisplatin alone, there was a $5-10 \%$ reduction in the cell viability compared with the DMSO control in four ovarian cancer cell lines: A2780cp, C13*, SKOV3 and ES-2 cells (Fig. $6 \mathrm{C})$. However, when the cells were co-treated with GSI and cisplatin together, we observed the synergistic enhancement of cisplatin-induced cytotoxicity, with a $17-38 \%$ reduction in the cell viability of all four ovarian cancer cell lines (Fig. 6C). To further explore whether blocking Notch1 signaling could enhance cisplatinmediated cell cytotoxicity in vivo, 5-week BALB/ $\mathrm{cAnN}$ nude mice were subcutaneously injected with the chemoresistant ovarian cancer cell line ES-2. When the tumors were palpable on Day 7, the mice were randomly divided into 4 groups. Each group was administered one treatment by intraperitoneal injection every two days: DMSO, GSI $(200 \mu \mathrm{g} / \mathrm{kg})$, cisplatin $(5 \mathrm{mg} / \mathrm{kg})$ or GSI (200 $\mu \mathrm{g} / \mathrm{kg}$ ) combined with cisplatin $(5 \mathrm{mg} / \mathrm{kg})$. When the mice were treated with GSI or cisplatin alone, the tumor growth was inhibited by $20 \%$ and $45 \%$, respectively, compared with DMSO group (Fig. 6D). However, co-treatment with GSI and cisplatin synergistically enhanced cisplatininduced cytotoxicity, resulting in a $73 \%$ reduction in tumor growth on day 18 (Fig. 6D). These results indicate that the JAG1/Notch1 signaling pathway is indispensable for cisplatin resistance in ovarian cancer cells.

\section{DISCUSSION:}

The acquisition of resistance during tumor progression and repeated challenges of chemotherapy is the major obstacle of clinical management of ovarian cancer [15, 31-33]. However, the underlying mechanisms leading to chemoresistance in ovarian cancer remain poorly understood. In this study, we identified that the loss of miR-199b-5p, mediated by increased DNA methylation, is associated with acquired cisplatin resistance via aberrant activation of JAG1-Notch1 signaling in ovarian cancer. Blocking the JAG1-Notch1 signaling axis by either reexpression of miR-199b-5p, siRNA-mediated JAG1 knockdown or treatment with the Notch-specific inhibitor $\gamma$-secretase (GSI) dramatically abrogated tumor growth and enhance cisplatin-induced cytotoxicity in vitro and in vivo in ovarian cancer cells. Our study provides a novel regulatory circuit in which the epigenetic machinery silences the expression of miRNAs to dysregulate the activity of the key signaling pathways involved in developing ovarian cancer chemoresistance.

Mounting evidence has suggested that the dysregulation of miRNAs causes aberrant upregulation of oncogenes or the downregulation of tumor suppressor genes which in turn leads to cancer initiation and progression [34-36]. In this study, miR-199b-5p was identified as a downregulated miRNA from two pairs of cisplatin sensitive vs. resistant ovarian cancer cell lines (A2780s vs. A2780cp and OV2008 vs. C13*) [15, 37, 38]. The cisplatin-resistant cell lines A2780cp and C13* were obtained from repetitive challenges of cisplatin treatment to A2780s and OV2008 cells. This repeated challenge of cisplatin treatment mimics the clinical situation in which the patient is repeatedly treated by cisplatin before they are in recurrence [39]. Interestingly, the downregulation of miR-199b-5p was progressively enhanced from early to advanced stages and low- to high-grade ovarian cancer tissue samples, indicating that the loss of miR$199 \mathrm{~b}-5 \mathrm{p}$ is involved in ovarian cancer progression. Accumulating evidence has documented that aberrant genetic and epigenetic alterations always occur during cancer progression, including in the progression of ovarian cancer [40-42]. These alterations result in abnormal activation of functional signaling, which in turn leads to so-called "acquired chemoresistance". Hence, acquired chemoresistance is proposed to be a dominant player in ovarian cancer [7, 43-45]. In this study, forced expression of miR-199b-5p could not only suppress ovarian cancer cell growth but also sensitize resistant ovarian cancer to cisplatin treatment in vitro and in vivo. These results suggest that miR-199b-5p plays a significant role in tumor suppression by inhibiting cell growth and enhancing the chemosensitivity of epithelial ovarian cancer. 
MiR-199b-5p was progressively downregulated from early to advanced stage and low- to high-grade ovarian cancer, suggesting that the loss of miR-199b-5p is the gradual result of epigenetic silencing mechanisms such as hypermethylation. Indeed, DNA hypermethylation has been frequently reported to silence tumor suppressor miRNAs in various human cancers, including ovarian cancer $[46,47]$. For instance, downregulation of the miR34 family is induced by promoter hypermethylation and leads to the pathological progression of epithelial ovarian cancer [48]. Our results demonstrate that the expression of miR-199b-5p could be restored in 5 out of 6 ovarian cancer cell lines using 5-Aza-dC-mediated DNA demethylation. MS-PCR, BGS and pyrosequencing analyses further confirmed that an increase in the DNA methylation of the promoter of miR-199b-5p in ovarian cancer cell lines. More importantly, although there is a limited number of ovarian cancer samples for pyrosequencing analysis, our data suggests that there is a progressive increase in DNA methylation that is inversely correlated with the expression of miR-199b-5p during the progression of ovarian cancer. Therefore, these findings support our hypothesis that the loss of miR-199b-5p is attributed to increased DNA methylation during tumor progression and repetitive treatment of chemotherapy in ovarian cancer.

Dysregulation of the JAG1-Notch1 signaling cascade has been shown to activate a wide range of oncogenes in the HES, HEY and MYC families, thereby leading to ovarian cancer progression and chemoresistance $[21,49,50]$. Platinum-based chemotherapy is the standard first-line regimen for ovarian cancer patients with advanced-stage disease. Cisplatin is the most common platinum-based compound capable of causing inter- and intra-strand DNA crosslinks that induces cell apoptosis with DNA damage [51, 52]. Previous studies have proposed that the aberrant activation of the JAG1Notch1 signaling pathway may protect cancer cells from cisplatin-induced cell apoptosis and that the signaling activity is inversely correlated with the cisplatin sensitivity of human cancers [53-57]. Moreover, Notch signaling is associated with tumor growth and angiogenesis [58, 59]. A recent study has suggested that the modulation of tumor angiogenesis by blocking VEGF signaling could reduce the chemoresistance of ovarian cancer [60], suggesting that JAG1/NOTCH1/neovascularization confers ovarian cancer chemoresistance. Indeed, our work provides compelling evidence that overexpressed JAG1 could enhance ovarian cancer cell proliferation, whereas depletion of JAG1 by siRNAs or suppression of Notch1 signaling by $\gamma$-secretase inhibitor (GSI) could sensitize chemoresistant ovarian cancer cells to cisplatin-induced cytotoxicity by in vitro and in vivo models, suggesting that the JAG1-Notch1 signaling axis plays a critical role in the development of ovarian cancer chemoresistance.

Recent studies have reported that the expression of JAG1 is modulated by miRNAs. For instance, JAG1 could be repressed by miR-34b in estrogen-dependent breast cancer cells [61] and by miR-524-5p in glioma [62]. In this study, miR-199b-5p was identified as another novel miRNA regulating the expression of JAG1 in ovarian cancer. We demonstrated that the forced expression of miR-199b-5p could suppress ovarian cancer cell growth and sensitize the cells to cisplatin-induced cytotoxicity. On the other hand, as a direct target of miR-199b-5p in ovarian cancer cells, JAG1 depletion by siRNAs also resulted in cell growth retardation and sensitization to cisplatin-induced cytotoxicity. In contrast, activating Notch1 signaling by JAG1 or repressing miR-199b-5p by anti-miR-199b-5p could induce the activity of JAG1Notch1 signaling in ovarian cancer cells. Therefore, this study suggests that the loss of miR-199b-5p increased the activation of JAG1-Notch1 signaling, which in turn promoted ovarian cancer progression and acquired chemoresistance. Thus far, this is the first report, to our knowledge, that the miR-199b-5p-JAG1-Notch1 signaling pathway is a novel regulatory circuit for acquired chemoresistance in ovarian cancer.

In conclusion, the findings in this study enhance our understanding of acquired chemoresistance in ovarian cancer during tumor progression or repetitive platinum-based chemotherapy. The epigenetic silencing of miR-199b-5p may at least partly activate JAG1-Notch1 signaling activity and promote acquired chemoresistance in ovarian cancer. Therefore, targeting the miR-199b-5pJAG1-Notch1 regulatory circuit might be a therapeutic approach in cisplatin-resistant ovarian cancer.

\section{MATERIALS AND METHODS:}

\section{Cell lines and clinical samples}

Ovarian cancer cell lines (A2780s, A2780cp, OV2008, C13*) (kindly provided by Prof. Benjamin K. Tsang, Department of Obstetrics and Gynecology, University of Ottawa), and SKOV3, OVCA433 and ES-2 (purchased from American Type Culture Collection, ATCC) used in this study were grown at $37^{\circ} \mathrm{C}$ with DMEM medium supplemented with $10 \%$ fetal bovine serum (FBS). Fresh snap-frozen surgical specimens of tumor tissues from 79 EOC patients completely resected at the Queen Mary Hospital (Hong Kong) were consecutively collected. All the clinical specimens used in the present study were approved by the local institutional ethics committee (IRB: UW 11-298).

\section{Plasmids and Drugs}

The pmR-ZsGreen1-miR-199b-5p expressing construct (Forward- TCTCAGCCCAAGCTTCCGCTC, Reverse- AATGTGAGTGGATCCTTGCAC, 657bp) 
was amplified and ligated into pmR-ZsGreen1 plasmid (Clontech, Mountain View, CA). The miRNA inhibitor targeting miR-199b-5p was purchased from Applied Biosystems (Product ID: AM10553, Applied Biosystems, Foster city, CA). The small interfere RNAs (Duplex Oligonucleotide) targeting JAG1 were purchased from IDT (Integrated DNA Technologies, Coralville, USA) (Supplementary Table 1). The JAG1 expressing plasmid (pCD-HA/JAG1) used for JAG1 expression was provided by Prof. Aly Karsan (British Columbia Cancer Research Centre, Canada), and pHES1-luc plasmid used for luciferase reporter assay was provided by Prof. Ryoichiro Kageyama (Kyoto University, Japan). Cisplatin (CDDP) was obtained from Calbiochem (Darmstadt, Germany) and was stocked at a concentration of $5 \mathrm{mg} / \mathrm{ml}$ at $-20^{\circ} \mathrm{C}$. 5-Aza2'-deoxycytidine (5-Aza-dC, Sigma Chemical Co., St Louis, MD, USA) at a concentration of $20 \mathrm{mM}$ was stored at $-20^{\circ} \mathrm{C}$ and freshly dissolved in culture medium before use. $\gamma$-secretase inhibitor (GSI XXI, Compound E, Merck, Darmstadt, Germany) was stocked at a concentration of $1 \mathrm{mM}$ at $-20^{\circ} \mathrm{C}$ and freshly diluted to $10 \mu \mathrm{M}$ in culture medium before use.

\section{RNA isolation and quantitative real-time RT-PCR}

Total RNA from cell lines and primary cancer tissue samples was prepared by TRIzol reagent (Invitrogen Life Technology). First-strand complementary DNA was synthesized and quantitative reverse transcriptionpolymerase chain reaction was done using the miRCURY LNA $^{\mathrm{TM}}$ Universal RT miRNA PCR Kit (Product No. 203450, Exiqon, Denmark) in an ABI 7500 system (Applied Biosystems). The miR-199b-5p probes were obtained from Exiqon (Product No. 204152). Each sample was performed in triplicate and normalized with human SNORD48 (Product No. 203903, Exiqon, Denmark). Bisulfite conversion, Methylation specific PCR (MS-PCR), Bisulfite Genomic Sequencing (BGS) and pyrosequencing analysis

Genomic DNA was extracted using the DNeasy Blood \& Tissue Kit (QIAGEN, Valencia, CA) in ovarian cancer cell lines and cancer samples. The genomic DNA was then applied for bisulfite conversion using the EZ DNA Methylation-Gold Kit (Zymo Research, Orange, California, USA) according to the manufacturer's protocol. The MS-PCR and BGS sequence was amplified by MyTaq ${ }^{\mathrm{TM}}$ HS Mix Reaction Buffer (Bioline, London, UK). The BGS amplified PCR products were cloned into the Topo TA vector (Bioline). Colonies were randomly picked for mini preparation and sequencing. The primers and PCR conditions for MSP and BGS are listed in (Supplementary Table 2.) Pyrosequencing assays were designed using PSQ Assay Design Software (version 1.0.6, Biotage). The primers for amplifying the pyrosequencing region of miR-199b-5p were forward
5'- GGGAAGAGTTATGTAAGTGTTGGAAAGA-3' and reverse 5'-AAAACTTCCCCTAACCCTTTC -3'. This assay amplifies a region of $357 \mathrm{bp}$ in advanced of miR-199b-5p (position -6,389--6,033), which includes ten $\mathrm{CpG}$ sites to be analyzed. These ten $\mathrm{CpG}$ sites were included in the BGS region.

\section{Cell viability assays}

Cell viability was evaluated by XTT assay and Focus formation assay. Approximately 2,000-3,000 cells were seeded into each well of a 96 -well plate. The medium was refreshed 24 hours after cell seeding containing appropriate concentration of cisplatin or $\gamma$-secretase inhibitor. XTT was measured by Cell Proliferation Kit II (Roche Biosciences, Indianapolis, IN, USA) according to the manufacturer's instructions. For focus formation assay, 5000 cells with stable expression of miRNA or control vector were seeded into 6 -well plates. The medium was replaced with fresh medium containing appropriate concentration of cisplatin 24 hours after cell seeding and grew for about 14 days during which fresh medium containing cisplatin was refreshed for every 4 days. Cells were stained with $1 \%$ crystal violet (Sigma-Alrich, St. Louis, MO, USA). Numbers of foci were counted after the cells dried. Experiments were performed in triplicates and results were expressed as the mean $\pm \mathrm{SD}$.

\section{Luciferase reporter assay}

Luciferase constructs were made by ligating oligonucleotides containing the wild-type (WT) or mutant sites (MUT) of the 3'UTR of JAG1 gene (position 135-141) into the multi-cloning site of the pmirGLO plasmid (Promega, Madison, WI) (Supplementary Table 3 ). HEK 293 cells were seeded into a 24-well plate and co-transfected with $100 \mathrm{ng}$ pmirGLO-JAG1 plasmid, pmR-199b plasmid and pmR-ZsGreen 1 empty vector for balance (400 $\mathrm{ng}$ in total), using Lipofectamine ${ }^{\mathrm{TM}}$ 2000 (Invitrogen). Luciferase activity was determined by the Dual-Luciferase Assay Kit (Promega) $48 \mathrm{~h}$ after transfection using a Fluorescence Spectrophotometer F-4500 (Promega).

\section{Western Blot}

Cells were harvested and lysed by RIPA Buffer (Sigma Chemical Co., St Louis, MD, USA). Samples containing equal amounts of protein were separated by SDS-PAGE and electroblotted onto Immobilon-P Transfer Membrane (Millipore Corporation, Bedford, MA). The membrane was blocked with 5\% no-fat milk, followed by incubation with antibodies specific for anti-JAG1 (1:500, 28H8, Cell Signaling Technology, 
Beverly, MA), anti-Notch1 (1:1000, C-20,sc-6014, Santa Cruz Biotechnology, Santa Cruz, CA) and anti- $\beta$-actin (1:5000, AC-74, Sigma Chemical Co), respectively. Blots were then incubated with goat anti-rabbit or anti-mouse secondary antibody conjugated to horseradish peroxidase (Amersham Pharmacia, Cleveland, $\mathrm{OH}$ ) accordingly. The signals were captured by FUJI Medical X-Ray Film (Fuji) and developed by the FUJI system.

\section{Immunohistochemistry (IHC) and in situ hybridization (ISH)}

The commercial tissue array slide (OVC1021, Pantomics) was deparaffinized in xylene and rehydrated in alcohol, then immersed in sodium citrate buffer (pH6) and boiled in boiled water for 20 minutes. $0.3 \%$ hydrogen peroxidase $\left(\mathrm{H}_{2} \mathrm{O}_{2}\right)$ was used to inhibit endogenous peroxidase. $10 \%$ normal rabbit serum was applied for blocking non-specific bindings for 45 minutes. Following this, slides were incubated with primary antibodies antiJAG1 monoclonal antibody $(1: 100)$ at predetermined dilutions at $4^{\circ} \mathrm{C}$ overnight. $0.1 \%$ Tween 20 (TBS-T) was used to wash the slides for three times. Staining was carried out following standard streptavidin-biotinperoidase complex method. Mayer's hematoxylin was used for counterstained. Two independent investigators were invited to review counterstained slides. Scores were then given to the stained slides according to the intensity and the percentage of the stained tissues.

In situ hybridization (ISH) was performed to evaluate the miR-199b-5p expression in a commercial tissue array (OVC1021, Pantomics) using the miRCURY LNA $^{\mathrm{TM}}$ microRNA ISH Optimization Kit 5 (FFPE) (Exiqon, Vedbaek, Denmark). In brief, the tissue array slide was deparaffinized and incubated with $20 \mu \mathrm{g} / \mathrm{ml}$ Proteinase-K for 40 minutes at $37^{\circ} \mathrm{C}$. Following this, the slide was dehydrated and hybridized with specific miR-199b-5p probe $(1: 500)$ at $50^{\circ} \mathrm{C}$ overnight. After hybridization, the slide was incubated with anti-DIG reagent (sheep anti-DIG-AP at 1:400) for 60 minutes at room temperature and applied to freshly prepared AP substrate and incubated for 2 hours at $30^{\circ} \mathrm{C}$ in a dark, humidifying chamber. Finally, it was stained for nuclear counter and mounted with mounting medium (Eukitt $\left.{ }^{\circledR}\right)$. The precipitate was allowed to settle overnight and the results were analyzed by light microscopy on the next day.

\section{In vivo tumorigenicity}

Ccancer cells with miR-199b-5p stably expression or vector control were injected subcutaneously into the right and left dorsal flank $\left(2 \times 10^{6}\right.$ per side $)$, respectively, of BALB/c nude mice (5 mice per group). When the tumors were palpable, cisplatin $(5 \mathrm{mg} / \mathrm{kg}$, Pharmachemie BV, Netherlands, Platosin, $1 \mathrm{mg} / \mathrm{ml}$ ) was injected into the mice in peritoneal every three days. Tumor size was observed by measuring the tumor volume calculating by the formula $\mathrm{V}=6 / \pi^{*}[(\mathrm{~L}+\mathrm{W}) / 2]^{3}$. Tumors were then excised after sacrifice. All animal experiments were approved by the Committee on the Use of Live Animals in Teaching and Research of The University of Hong Kong (CULATR 2053-09),

\section{Statistical analysis}

Statistical analysis was carried out using SPSS 14.0 (SPSS). Student's t-test and the Mann-Whitney test were used. The results were expressed as mean \pm SD. $\chi 2$ test or Fisher's exact test was used to analyze the association of miR-199b-5p and JAG1 gene expression and clinicopathological parameters. Differences were considered significant when $\mathrm{p} \leq 0.05$.

\section{ACKNOWLEDGEMENTS:}

We thank Prof. B. K. Tsang (Department of Obstetrics and Gynecology, University of Ottawa) for providing cisplatin-sensitive (A2780s and OV2008) and cisplatin-resistant (A2780cp and C13*) ovarian cancer cell lines, Prof. Aly Karsan (British Columbia Cancer Research Centre, Canada) for providing the JAG1 expressing plasmid (pCD-HA/JAG1), and Prof. Ryoichiro Kageyama (Kyoto University, Japan) for providing pHES1-luc plasmid.

\section{Statement of author contributions:}

ML and DC designed research; ML, SL and PC performed the experiments; DC, SL and $\mathrm{HN}$ contributed new reagents-analytic tools; ML, DC, MS, JY and HN analyzed and interpreted data; ML and DC wrote the manuscript; DC and HN study supervision. All authors were involved in editing the manuscript and had final approval of the submitted and published versions.

\section{REFERENCES:}

1. Hennessy BT, Coleman RL and Markman M. Ovarian cancer. Lancet. 2009; 374(9698):1371-1382.

2. Bast RC, Jr., Hennessy B and Mills GB. The biology of ovarian cancer: new opportunities for translation. Nat Rev Cancer. 2009; 9(6):415-428.

3. Agarwal R and Kaye SB. Ovarian cancer: strategies for overcoming resistance to chemotherapy. Nat Rev Cancer. 2003; 3(7):502-516.

4. Geisler JP, Manahan KJ and Wiemann MC. Chemotherapy for ovarian cancer: an evidence-based approach. Minerva Ginecol. 2004; 56(6):539-545.

5. Gottesman MM. Mechanisms of cancer drug resistance. 
Annu Rev Med. 2002; 53:615-627.

6. Cannistra SA. Cancer of the ovary. N Engl J Med. 2004; 351(24):2519-2529.

7. Zeller C, Dai W, Steele NL, Siddiq A, Walley AJ, Wilhelm-Benartzi CSM, Rizzo S, van der Zee A, Plumb JA and Brown R. Candidate DNA methylation drivers of acquired cisplatin resistance in ovarian cancer identified by methylome and expression profiling. Oncogene. 2012.

8. Dumontet C and Sikic BI. Mechanisms of action of and resistance to antitubulin agents: microtubule dynamics, drug transport, and cell death. J Clin Oncol. 1999; 17(3):10611070 .

9. Muggia F. Platinum compounds 30 years after the introduction of cisplatin: implications for the treatment of ovarian cancer. Gynecol Oncol. 2009; 112(1):275-281.

10. Fojo T. Multiple paths to a drug resistance phenotype: mutations, translocations, deletions and amplification of coding genes or promoter regions, epigenetic changes and microRNAs. Drug Resist Updat. 2007; 10(1-2):59-67.

11. Pogribny IP, Filkowski JN, Tryndyak VP, Golubov A, Shpyleva SI and Kovalchuk O. Alterations of microRNAs and their targets are associated with acquired resistance of MCF-7 breast cancer cells to cisplatin. Int J Cancer. 2010; 127(8):1785-1794.

12. Hwang JH, Voortman J, Giovannetti E, Steinberg SM, Leon LG, Kim YT, Funel N, Park JK, Kim MA, Kang GH, Kim SW, Del Chiaro M, Peters GJ and Giaccone G. Identification of microRNA-21 as a biomarker for chemoresistance and clinical outcome following adjuvant therapy in resectable pancreatic cancer. PLoS One. 2010; 5(5):e10630.

13. Gong C, Yao Y, Wang Y, Liu B, Wu W, Chen J, Su F, Yao $\mathrm{H}$ and Song E. Up-regulation of miR-21 Mediates Resistance to Trastuzumab Therapy for Breast Cancer. Journal of Biological Chemistry. 2011; 286(21):1912719137.

14. Galluzzi L, Morselli E, Vitale I, Kepp O, Senovilla L, Criollo A, Servant N, Paccard C, Hupe P, Robert T, Ripoche H, Lazar V, Harel-Bellan A, Dessen P, Barillot E and Kroemer G. miR-181a and miR-630 regulate cisplatininduced cancer cell death. Cancer Res. 2010; 70(5):17931803.

15. Chan DW, Liu VW, Tsao GS, Yao KM, Furukawa T, Chan KK and Ngan HY. Loss of MKP3 mediated by oxidative stress enhances tumorigenicity and chemoresistance of ovarian cancer cells. Carcinogenesis. 2008; 29(9):17421750.

16. Steg AD, Katre AA, Goodman B, Han HD, Nick AM, Stone RL, Coleman RL, Alvarez RD, Lopez-Berestein G, Sood $\mathrm{AK}$ and Landen CN. Targeting the notch ligand JAGGED1 in both tumor cells and stroma in ovarian cancer. Clin Cancer Res. 2011; 17(17):5674-5685.

17. Kim A, Enomoto T, Serada S, Ueda Y, Takahashi T, Ripley B, Miyatake T, Fujita M, Lee CM, Morimoto K, Fujimoto
M, Kimura T and Naka T. Enhanced expression of Annexin A4 in clear cell carcinoma of the ovary and its association with chemoresistance to carboplatin. Int J Cancer. 2009; 125(10):2316-2322.

18. Suzuki S, Yoshikawa T, Hirosawa T, Shibata K, Kikkawa F, Akatsuka Y and Nakatsura T. Glypican-3 could be an effective target for immunotherapy combined with chemotherapy against ovarian clear cell carcinoma. Cancer Sci. 2011; 102(9):1622-1629.

19. Datta J, Kutay H, Nasser MW, Nuovo GJ, Wang B, Majumder S, Liu CG, Volinia S, Croce CM, Schmittgen TD, Ghoshal K and Jacob ST. Methylation mediated silencing of MicroRNA-1 gene and its role in hepatocellular carcinogenesis. Cancer Res. 2008; 68(13):5049-5058.

20. Lu L, Katsaros D, de la Longrais IA, Sochirca O and Yu H. Hypermethylation of let-7a-3 in epithelial ovarian cancer is associated with low insulin-like growth factor-II expression and favorable prognosis. Cancer Res. 2007; 67(21):1011710122.

21. Choi JH, Park JT, Davidson B, Morin PJ, Shih Ie M and Wang TL. Jagged-1 and Notch3 juxtacrine loop regulates ovarian tumor growth and adhesion. Cancer Res. 2008; 68(14):5716-5723.

22. Simon DP, Giordano TJ and Hammer GD. Upregulated JAG1 enhances cell proliferation in adrenocortical carcinoma. Clin Cancer Res. 2012; 18(9):2452-2464.

23. Shimizu M, Cohen B, Goldvasser P, Berman H, Virtanen $\mathrm{C}$ and Reedijk M. Plasminogen activator uPA is a direct transcriptional target of the JAG1-Notch receptor signaling pathway in breast cancer. Cancer Res. 2011; 71(1):277-286.

24. Rodilla V, Villanueva A, Obrador-Hevia A, RobertMoreno A, Fernandez-Majada V, Grilli A, Lopez-Bigas N, Bellora N, Alba MM, Torres F, Dunach M, Sanjuan X, Gonzalez S, Gridley T, Capella G, Bigas A, et al. Jagged1 is the pathological link between Wnt and Notch pathways in colorectal cancer. Proc Natl Acad Sci U S A. 2009; 106(15):6315-6320.

25. Wang Z, Li Y, Banerjee S, Kong D, Ahmad A, Nogueira V, Hay N and Sarkar FH. Down-regulation of Notch-1 and Jagged-1 inhibits prostate cancer cell growth, migration and invasion, and induces apoptosis via inactivation of Akt, mTOR, and NF-kappaB signaling pathways. J Cell Biochem. 2010; 109(4):726-736.

26. Meng RD, Shelton CC, Li YM, Qin LX, Notterman D, Paty $\mathrm{PB}$ and Schwartz GK. gamma-Secretase inhibitors abrogate oxaliplatin-induced activation of the Notch-1 signaling pathway in colon cancer cells resulting in enhanced chemosensitivity. Cancer Res. 2009; 69(2):573-582.

27. Osipo C, Patel P, Rizzo P, Clementz AG, Hao L, Golde TE and Miele L. ErbB-2 inhibition activates Notch-1 and sensitizes breast cancer cells to a gamma-secretase inhibitor. Oncogene. 2008; 27(37):5019-5032.

28. Wang Z, Zhang Y, Banerjee S, Li Y and Sarkar FH. Inhibition of nuclear factor kappab activity by genistein 
is mediated via Notch-1 signaling pathway in pancreatic cancer cells. Int J Cancer. 2006; 118(8):1930-1936.

29. Shimizu K, Chiba S, Saito T, Kumano K, Hamada Y and Hirai H. Functional diversity among Notch1, Notch2, and Notch3 receptors. Biochem Biophys Res Commun. 2002; 291(4):775-779.

30. Ranganathan P, Weaver KL and Capobianco AJ. Notch signalling in solid tumours: a little bit of everything but not all the time. Nature Reviews Cancer. 2011; 11(5):338-351.

31. Marchini S, Fruscio R, Clivio L, Beltrame L, Porcu L, Nerini IF, Cavalieri D, Chiorino G, Cattoretti G, Mangioni C, Milani R, Torri V, Romualdi C, Zambelli A, Romano M, Signorelli M, et al. Resistance to platinum-based chemotherapy is associated with epithelial to mesenchymal transition in epithelial ovarian cancer. Eur J Cancer. 2013; 49(2):520-530.

32. Shahzad MM, Lopez-Berestein G and Sood AK. Novel strategies for reversing platinum resistance. Drug Resist Updat. 2009; 12(6):148-152.

33. Ranganathan AC, Zhang L, Adam AP and Aguirre-Ghiso JA. Functional coupling of p38-induced up-regulation of $\mathrm{BiP}$ and activation of RNA-dependent protein kinase-like endoplasmic reticulum kinase to drug resistance of dormant carcinoma cells. Cancer Res. 2006; 66(3):1702-1711.

34. Ma L and Weinberg RA. MicroRNAs in malignant progression. Cell Cycle. 2008; 7(5):570-572.

35. Santarpia L, Nicoloso $M$ and Calin GA. MicroRNAs: a complex regulatory network drives the acquisition of malignant cell phenotype. Endocr Relat Cancer. 2010; 17(1):F51-75.

36. Inui M, Martello $\mathrm{G}$ and Piccolo S. MicroRNA control of signal transduction. Nat Rev Mol Cell Biol. 2010; 11(4):252-263.

37. Yuan ZQ, Feldman RI, Sussman GE, Coppola D, Nicosia SV and Cheng JQ. AKT2 inhibition of cisplatin-induced $\mathrm{JNK} / \mathrm{p} 38$ and Bax activation by phosphorylation of ASK1: implication of AKT2 in chemoresistance. J Biol Chem. 2003; 278(26):23432-23440.

38. Al-Bahlani S, Fraser M, Wong AY, Sayan BS, Bergeron R, Melino G and Tsang BK. P73 regulates cisplatin-induced apoptosis in ovarian cancer cells via a calcium/calpaindependent mechanism. Oncogene. 2011; 30(41):4219-4230.

39. Eltabbakh GH and Awtrey CS. Current treatment for ovarian cancer. Expert Opin Pharmacother. 2001; 2(1):109124.

40. van Jaarsveld MT, Helleman J, Berns EM and Wiemer EA. MicroRNAs in ovarian cancer biology and therapy resistance. Int J Biochem Cell Biol. 2010; 42(8):1282-1290.

41. Ashworth A, Lord CJ and Reis-Filho JS. Genetic interactions in cancer progression and treatment. Cell. 2011; 145(1):30-38 .

42. Balch C, Fang F, Matei DE, Huang TH and Nephew KP. Minireview: epigenetic changes in ovarian cancer. Endocrinology. 2009; 150(9):4003-4011.
43. Yang H, Kong W, He L, Zhao JJ, O’Donnell JD, Wang J, Wenham RM, Coppola D, Kruk PA, Nicosia SV and Cheng JQ. MicroRNA expression profiling in human ovarian cancer: miR-214 induces cell survival and cisplatin resistance by targeting PTEN. Cancer Res. 2008; 68(2):425433.

44. Ye G, Fu G, Cui S, Zhao S, Bernaudo S, Bai Y, Ding Y, Zhang Y, Yang BB and Peng C. MicroRNA 376c enhances ovarian cancer cell survival by targeting activin receptorlike kinase 7: implications for chemoresistance. J Cell Sci. 2011; 124(Pt 3):359-368.

45. Ibrahim N, He L, Leong CO, Xing D, Karlan BY, Swisher EM, Rueda BR, Orsulic S and Ellisen LW. BRCA1Associated Epigenetic Regulation of p73 Mediates an Effector Pathway for Chemosensitivity in Ovarian Carcinoma. Cancer Research. 2010; 70(18):7155-7165.

46. Lopez-Serra P and Esteller M. DNA methylation-associated silencing of tumor-suppressor microRNAs in cancer. Oncogene. 2012; 31(13):1609-1622.

47. Zhang L, Volinia S, Bonome T, Calin GA, Greshock J, Yang N, Liu CG, Giannakakis A, Alexiou P, Hasegawa K, Johnstone CN, Megraw MS, Adams S, Lassus H, Huang J, Kaur S, et al. Genomic and epigenetic alterations deregulate microRNA expression in human epithelial ovarian cancer. Proc Natl Acad Sci U S A. 2008; 105(19):7004-7009.

48. Corney DC, Hwang CI, Matoso A, Vogt M, FleskenNikitin A, Godwin AK, Kamat AA, Sood AK, Ellenson LH, Hermeking $\mathrm{H}$ and Nikitin AY. Frequent downregulation of miR-34 family in human ovarian cancers. Clin Cancer Res. 2010; 16(4):1119-1128.

49. Integrated genomic analyses of ovarian carcinoma. Nature. 2011; 474(7353):609-615.

50. Hopfer O, Zwahlen D, Fey MF and Aebi S. The Notch pathway in ovarian carcinomas and adenomas. Br J Cancer. 2005; 93(6):709-718.

51. Niedner H, Christen R, Lin X, Kondo A and Howell SB. Identification of genes that mediate sensitivity to cisplatin. Mol Pharmacol. 2001; 60(6):1153-1160.

52. Nehme A, Baskaran R, Aebi S, Fink D, Nebel S, Cenni B, Wang JY, Howell SB and Christen RD. Differential induction of c-Jun NH2-terminal kinase and c-Abl kinase in DNA mismatch repair-proficient and -deficient cells exposed to cisplatin. Cancer Res. 1997; 57(15):3253-3257.

53. Ravi D, Wiles AM, Bhavani S, Ruan J, Leder P and Bishop AJ. A network of conserved damage survival pathways revealed by a genomic RNAi screen. PLoS Genet. 2009; 5(6): e1000527.

54. Aktas S, Zadeoglulari Z, Ercetin P and Olgun N. The effect of differentiating and apoptotic agents on notch signalling pathway in hepatoblastoma. Hepatogastroenterology. 2010; 57(101):891-898.

55. Liu YP, Yang CJ, Huang MS, Yeh CT, Wu AT, Lee YC, Lai TC, Lee CH, Hsiao YW, Lu J, Shen CN, Lu PJ and Hsiao M. Cisplatin selects for multidrug-resistant CD133+ 
cells in lung adenocarcinoma by activating Notch signaling. Cancer Res. 2013; 73(1):406-416.

56. McAuliffe SM, Morgan SL, Wyant GA, Tran LT, Muto KW, Chen YS, Chin KT, Partridge JC, Poole BB, Cheng KH, Daggett J, Jr., Cullen K, Kantoff E, Hasselbatt K, Berkowitz J, Muto MG, et al. Targeting Notch, a key pathway for ovarian cancer stem cells, sensitizes tumors to platinum therapy. Proc Natl Acad Sci U S A. 2012; 109(43):E2939-2948.

57. Zhang ZP, Sun YL, Fu L, Gu F, Zhang L and Hao XS. Correlation of Notch1 expression and activation to cisplatinsensitivity of head and neck squamous cell carcinoma. Ai Zheng. 2009; 28(2):100-103.

58. Kofler NM, Shawber CJ, Kangsamaksin T, Reed HO, Galatioto $J$ and Kitajewski J. Notch signaling in developmental and tumor angiogenesis. Genes Cancer. 2011; 2(12):1106-1116.

59. Stany MP, Vathipadiekal V, Ozbun L, Stone RL, Mok SC, Xue H, Kagami T, Wang Y, McAlpine JN, Bowtell D, Gout PW, Miller DM, Gilks CB, Huntsman DG, Ellard SL, Wang YZ, et al. Identification of novel therapeutic targets in microdissected clear cell ovarian cancers. PLoS One. 2011; 6(7):e21121.

60. Vecchione A, Belletti B, Lovat F, Volinia S, Chiappetta G, Giglio S, Sonego M, Cirombella R, Onesti EC, Pellegrini P, Califano D, Pignata S, Losito S, Canzonieri $\mathrm{V}$, Sorio R, Alder $\mathrm{H}$, et al. A microRNA signature defines chemoresistance in ovarian cancer through modulation of angiogenesis. Proc Natl Acad Sci U S A. 2013; 110(24):9845-9850.

61. Lee YM, Lee JY, Ho CC, Hong QS, Yu SL, Tzeng CR, Yang PC and Chen HW. miRNA-34b as a tumor suppressor in estrogen-dependent growth of breast cancer cells. Breast Cancer Res. 2011; 13(6):R116.

62. Chen L, Zhang W, Yan W, Han L, Zhang K, Shi Z, Zhang J, Wang Y, Li Y, Yu S, Pu P, Jiang C, Jiang T and Kang C. The Putative Tumor Suppressor miR-524-5p Directly Targets Jagged-1 and Hes-1 in Glioma. Carcinogenesis. 2012. 